\title{
Design and Implementation of a Virtual Reality System for Treating Highway Phobias: VRStreet
}

Jorge Fuentes ${ }^{1}$, Rodrigo Nieto ${ }^{2}$, Francisca Melis ${ }^{2}$, Luz María González ${ }^{2}$, Gonzalo M Rojas ${ }^{1,3,4,5}$, Lina Ortiz ${ }^{2}$, Rodrigo Erazo ${ }^{2}$, Marcelo Gálvez ${ }^{1,3,4,5}$

${ }^{1}$ Medical Biomodeling Laboratory, Department of Radiology, Clinica las Condes, Lo Fontecilla 441, Santiago, Chile

${ }^{2}$ Department of Psychiatry, Clinica las Condes, Lo Fontecilla 441, Santiago, Chile

${ }^{3}$ Laboratory of Medical Image Processing, Department of Radiology, Clinica las Condes, Lo Fontecilla 441, Santiago, Chile

${ }^{4}$ Department of Radiology, Clinica las Condes, Lo Fontecilla 441, Santiago, Chile

${ }^{5}$ Advanced, Epilepsy Center, Clinica las Condes, Lo Fontecilla 441, Santiago, Chile

\section{Corresponding Author:}

Gonzalo M. Rojas

e-mail: gonzalo.rojas.costa@gmail.com

telephone: 56-2-22105170 


\title{
Design and Implementation of a Virtual Reality System for Treating Highway Phobias: VRStreet
}

\author{
Abstract \\ To feel fear in a specific situation is a normal human experience, however, when this fear \\ or aversion becomes excessive and disrupts the day to day life of an individual, it is said \\ the person suffers from a type of anxiety disorder called phobia. One common type of \\ treatment for phobias is exposure therapy (professionals expose the patient gradually to \\ the feared object or situation).
}

The objective of this paper is to implement a Virtual Reality system that simulates a real highway environment which allows to treat patients affected by highway phobias in a safe place.

In cooperation with psychologists and psychiatrists, an action protocol was conducted to create and recreate the variables of the virtual environment to which the patient will be subjected to. Once this was completed, a Virtual Reality application was made that simulates a realistic highway which includes exits, overpasses, underpasses, and tunnels, among others.

This hardware/software system will include Oculus Rift DK2 VR glasses in order to create an immersive environment that the patient can consider real and who will be able to interact with it. The performance of the vehicle was programmed through physical responses similar to reality as well as techniques of artificial intelligence in the vehicles that will interact with the one controlled by the patient. Also, this system includes a steering wheel, pedals, and a gearshift (manual or automatic).

We think that this system will contribute to treating highway phobias, allowing the psychiatrist or psychologist to carry out therapy in an appropriate manner and through the support of technology the professional will have the ability to simulate the anxiogenic environment in a realistic manner so as to achieve effective treatment. In a future work, we must quantify the possible benefits of this type of VR system in phobia patients.

Keywords: virtual reality; phobias; highway phobias; Oculus Rift; VR; exposure therapy; VRET; specific phobias

\section{Introduction}

\section{Phobias}

A Specific Phobia is, according to DSM-5 criteria, an irrational, excessive and intense fear of a specific situation or object, and when facing that situation or object, the patient has an immediate anxious reaction. Due to simple conditioning, this causes anxious anticipation and a behavioral pattern which seeks to avoid said object or situation, which in turn causes quality of life to deteriorate. Typical examples are phobias to flying, heights, animals, and 
blood. Phobias can be divided into animals, environmental, situational and bloodinjections-injury (American Psychiatric Association, 2013).

Anxiety Disorders are a very common category of mental illness in the population with a lifetime prevalence of more than 15\% around the world (Kessler et al, 2009), and among these, Specific Phobias are the most common problem, with lifetime prevalence ranging from 6 to $12 \%$ of the population (Silverman \& Moreno, 2005). In Chile, according to the latest epidemiological studies, the lifetime prevalence of Anxiety Disorders in adults is $17.9 \%$ (Vicente et al, 2002), and, although there is no specific data about the prevalence of phobias, most likely it will be similar to the global tendency. In recent years, particularly after urban highways became a part of Greater Santiago, although there is no epidemiological data with regards to phobias, an increase in spontaneous medical consultations for highway phobias has been observed.

Psychotherapies based on exposure, especially live, have proved to be the most effective in decreasing phobic anxieties and the associated evasive behavior more so than pharmacological treatment (Hamm, 2009). The substitution of live exposure for a simulated environment using virtual reality arose as an attractive alternative for managing phobic anxieties due to the greater overall safety of the setting and because it was less threatening for patients, which in turn reduced overall resistance to treatment. Since the beginning of the 90's decade, multiple studies, revisions, and meta-analyses have provided evidence about the use of therapies based on Virtual Reality (VR) for a wide range of clinical conditions, but in particular for Phobias, in which they have proved to be highly effective (Botella et al, 2017).

\section{Virtual Reality}

Virtual Reality (VR) is a three-dimensional simulation generated or commonly assisted by a computer in which the user has the sensation of belonging to and being able to interact with the virtual environment created or simulated.

Virtual Reality permits the interaction of three-dimensional worlds in a natural manner; the user can perform actions within the virtual model such as travel, move, walk through the environment or move things and in the manner create situations that are very similar to real life experience. In order to achieve an immersion as similar to reality as possible, an application or simulation represented in virtual reality must at least have or emphasize its most important aspects in the simulation, interaction, and perception.

Within the virtual reality systems, there are two types:

- Immersive Systems: Immersive systems are those systems in which the user feels that he/she is in a virtual world that is being explored. These types of systems use different devices called accessories which could be special gloves, special suits, goggles or helmets. Goggles and helmets allow the user to visualize the virtual world through them and in point of fact, they are the main element that makes the user feel immersed in the world. These types of systems are ideal for training and simulation applications.

- Non immersive: Non immersive or desk systems are those in which the screen is the window to the virtual world and interaction takes place through a keyboard, microphone, mouse or joystick. These types of systems are frequently used as a means of 
entertainment and although they do not offer full immersion, they are a good low-cost alternative.

VR Exposure Therapy (VRET) has been previously assessed in an empirical and theoretical manner as an appropriate technique for treating specific phobias (Botella et al., 2017; Morina et al, 2015; Krijn et al; 2004). VRET has been used for arachnophobia (Miloff et al, 2016; Shiban et al, 2015; Garcia-Palacios et al, 2002; Shiban et al, 2015; Morina et al, 2015), acrophobia (Krijn et al, 2004; Morina et al, 2015), flight phobia (Botella et al., 2004; Rothbaum et al, 2000; Rothbaum et al, 1997), dental phobia (Gujjar et al., 2017), fear of falling (Levy et al., 2016), claustrophobia (Botella et al., 2000) and for social anxiety (Ben-Moussa et al., 2017; Bouchard, 2011). There is also a Spanish Company called Virtualret, which markets virtual reality systems designed to treat different type of phobias (public speaking, flight phobia, acrophobia, phobia to blood or injections, claustrophobia, animal phobias, etc.).

The proposal of this work is to implement a computerized system, using virtual reality, designed to treat patients who have been previously diagnosed with some kind of phobia. The system would specifically treat patients with highway phobias and the system proposed here will be implemented simulating Chilean highways.

\section{Implementation}

The following hardware and software elements were used to develop the system:

\section{Hardware:}

- Workstation: Used to develop 3D visualization applications; it can also interact with VR sensors and lenses.

- Oculus Rift DK2: Virtual reality lenses that allow to visualize more realistically in 3D and with greater immersion the processed models. (Reference: https://www.oculus.com/dk2/) - Logitech G27 Steering Wheel: A set of pedals, gearshifts and steering wheels with a turning capacity of $900^{\circ}$ used for driving simulations.

(http://support.logitech.com/en_us/product/g27-racing-wheel)

\section{Software:}

- Unity3D 5.x: Graphic Engine, software used to develop visualization software in addition to manipulating the processed models as mesh. (Reference: https://unity3d.com/). In this project, add-ons were used which in a certain manner helped to create the assets and environments in the application, such as:

- RoadArchitect (MicroGSD; https://github.com/MicroGSD/RoadArchitect): add-on that allows to create complex systems of roads and intersections.

- Realistic Car Controller (BoneCracker Gamest; https://www.assetstore.unity3d.com/en/\#!/content/16296): Simulation of the physical vehicle characteristics and performance. It allows the vehicle, while being driven, to perform as close to reality as possible, for example, suspension, mass transfer, transmission.

- WorldComposer (Nathaniel Doldersum); https://www.assetstore.unity3d.com/en/\#!/content/13238): a tool for retrieving real elevation data and satellite images of our world.

- $\quad$ iTS - Intelligent Traffic System (José Garrido); https://www.assetstore.unity3d.com/en/\#!/content/23564): This add-on permits to 
simulate traffic and the direction of the same thus allowing for interaction with other elements encountered during the simulation such as containment barriers.

- 3ds Max (Autodesk, Inc. San Rafael, CA, USA. www.autodesk.com): 3D modeling and editing software used to create elements such as the vehicle used in the simulation as well as other objects that interact with the environment, for example, tunnels, signs, vegetation, etc.

\section{Virtual Reality System:}

Using Unity3D and 3ds Max the required environment is generated for treating phobias to driving on urban highways with tunnels. The model of vehicle used for this purpose is a replica of a fifth generation BMW Series 3 with a coupe body (Figure 1). The highway is similar to the "Costanera Norte" urban highway

(http://web.costaneranorte.cl/autopista/mapa/; Figure 2) going west to east and east to west. In addition to creating the environment, pedals, gearshift and steering wheel functions are also incorporated as well as FFB (force feedback) so as to achieve a greater level of simulation and interaction with the environment.

An example of highway simulation using Virtual Reality can be seen in the video https://youtu.be/apWEmJ474B0

In order to recreate a highway, height maps taken from Google Maps were used (Google Inc. Mountain View, CA, USA. www.google.com), so as to obtain real elevations and these same maps were used as reference for creating the highway sections. The textures of the land also were taken from Google Maps satellite images (Figure 2).

\section{Illustration}

A driving simulation system using Virtual Reality is obtained in order to achieve a high level of immersion in the same which is designed to treat, through a gradual exposure method, patients who suffer from highway phobias.

When using the system, the specialist is able to choose the initial level of exposure for the patient undergoing treatment such as, for example, being able to decide between two highways, with two directions each one:

- Route 5 Northbound (http://www.scada.cl/vista-satelital.htm): Section of interurban highway which has a low level of driving difficulty due to the low amount of curves it presents; the chosen section can be North-South or South-North. This possibility of choice is aimed at involving the patient in the system and learns to feel at ease using it, in a controlled environment that is easy to drive in.

- Costanera Norte Highway: Urban highway, almost entirely simulated, of complex driving conditions due to its underground sections, bridges, elevation changes, traffic, and curves. This highway has been specifically intended and designed for specific treatment of the phobia since it exposes the patient directly to a daily traffic situation with complete stops within the tunnels or on the highway itself due to accidents (Figure 3 ). 
In addition to choosing which section will be simulated, the time frame in which the simulation will begin can also be chosen (Figures 4, 5), from among the following:

- $\quad$ Morning (between 6:00 a.m. and 12:59 p.m.; Figure 6)

- Afternoon (between 1:00 p.m. and 7:59 p.m.; Figure 7)

- $\quad$ Evening (from 8:00 p.m.; Figure 8)

If the starting time is not chosen, it will begin in the morning by default. For the effects of simulation for the transition between day - night, morning-afternoon, afternoon-evening, a reference of a one hour day is used.

Within the environment, once the simulation has begun, the specialist can select scenario modifications thus being able to make the driving conditions of the patient more or less complex. The parameters which can be chosen and their level of modification are the following:

- Climate (there exists a transition between the dominant climate and the one that has been chosen):

$\begin{array}{ll}\circ & \text { Cloudy } \\ \circ & \text { Partly Cloudy } \\ \circ & \text { Rain } \\ \circ & \text { Storm } \\ \circ & \text { Partly Sunny } \\ \circ & \text { Sunny } \\ \circ & \text { Scattered Clouds } \\ \circ & \text { Overcast } \\ \circ & \text { Heavy Rain } \\ \circ & \text { Fall conditions (windy, falling leaves) }\end{array}$

- Traffic:

0 Light, 20 vehicles within the viewing radius of the patient.

- Moderate, 40 vehicles.

- Heavy, 60 vehicles.

- Transmission:

- Manual/Sequential

- Automatic

- $\quad$ Speed Limit (maximum speed limit):
○ $80 \mathrm{~km} / \mathrm{h}$
- $120 \mathrm{~km} / \mathrm{h}$
○ $160 \mathrm{~km} / \mathrm{h}$

In order to drive the vehicle, a Logitech G27 steering wheel in manual transmission mode is used as the gear selector which for this model of vehicle consists of 6 gears in addition to reverse gear. Three pedals are used, the accelerator, brake, and clutch. If sequential transmission is selected, only the accelerator and brake pedals are used. Paddle Shifters, located behind the steering wheel are used to change the speed. The right Paddle Shift with the + symbol is used to increase the speed while the left Paddle Shift with the symbol is used to decrease the speed. Just as in the manual transmission mode, this version uses 6 gears as well as the reverse gear. 
If automatic transmission is chosen, the same pedals will be used as in sequential transmission and the patient only interacts with the paddle shifters if reverse gear is necessary.

\section{Discussion}

A low cost virtual reality system that simulates driving a vehicle along the Costanera Norte highway in Santiago, Chile has been described here. This simulation includes vehicular traffic, collisions, changes from day to night and from sunny to cloudy.

It is necessary to validate the VRStreet system and its benefit for patients diagnosed with highway phobias through variable exposure therapy in an amount of patients yet to be defined. The ability of the patient to use the VRStreet system must be monitored in addition to being able to measure the level of anxiety prior and post a VRStreet session and if any symptoms such as dizziness, nausea, vomiting, headaches, sweating, trembling among others occurred the session.

The main advantage of a system such as VRStreet is that the intensity and duration of the therapy is easily supervised and controlled by the physician whether in the physician's office or in an adjoining room where the patient is interacting with the VR system.

Unforeseen events can also be controlled further decreasing the risk of the intervention.

We hope this initiative will be of great help for patients with highway phobia since it allows them to undergo an efficient systematic desensibilization treatment that simulates a real highway through the use of technological support which makes them feel immersed in the very driving conditions that produce their fears. 


\section{FIGURES}

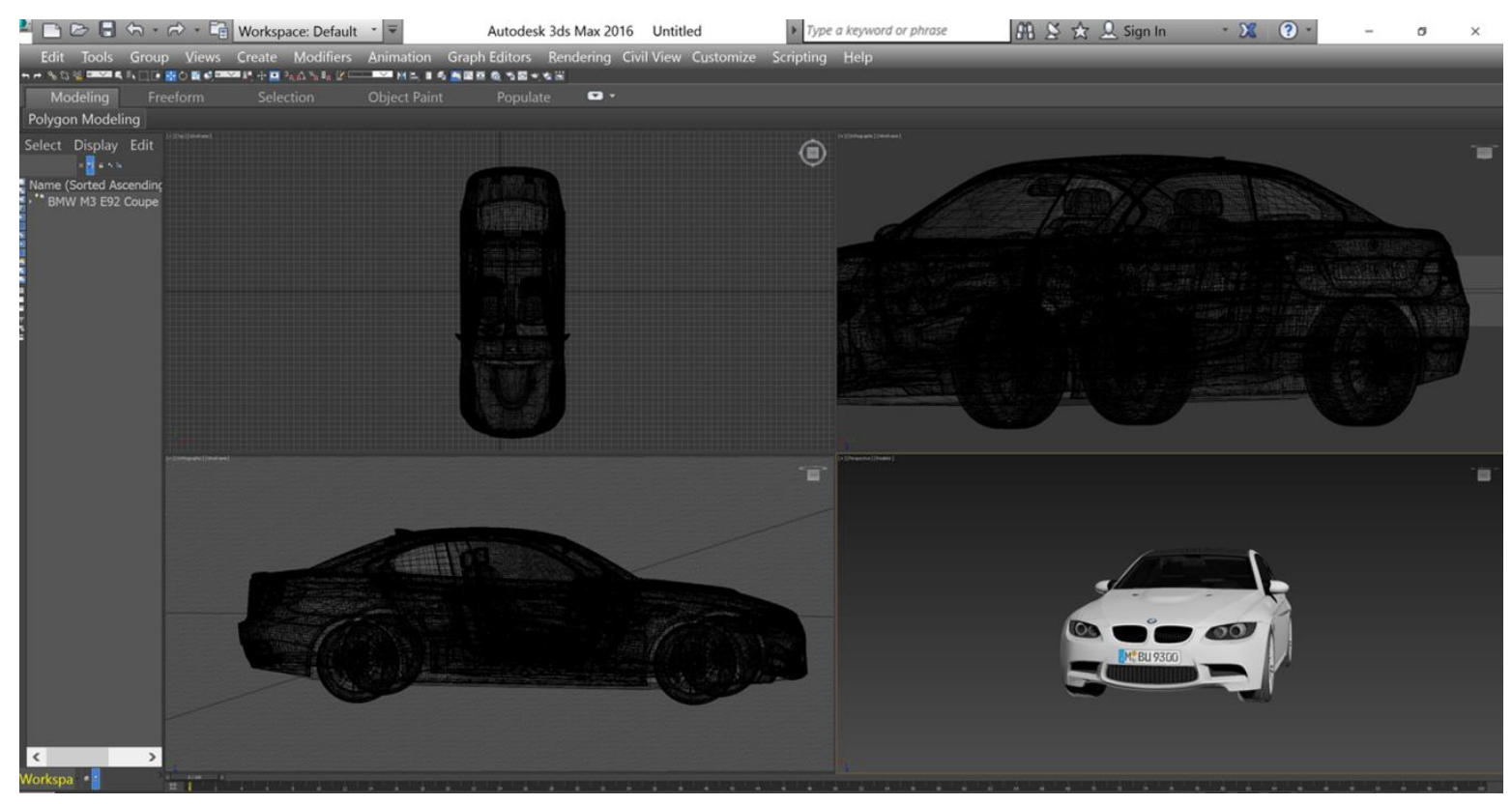

Figure 1: Mesh and different views of the fifth generation series BMW vehicle used in VRStreet.

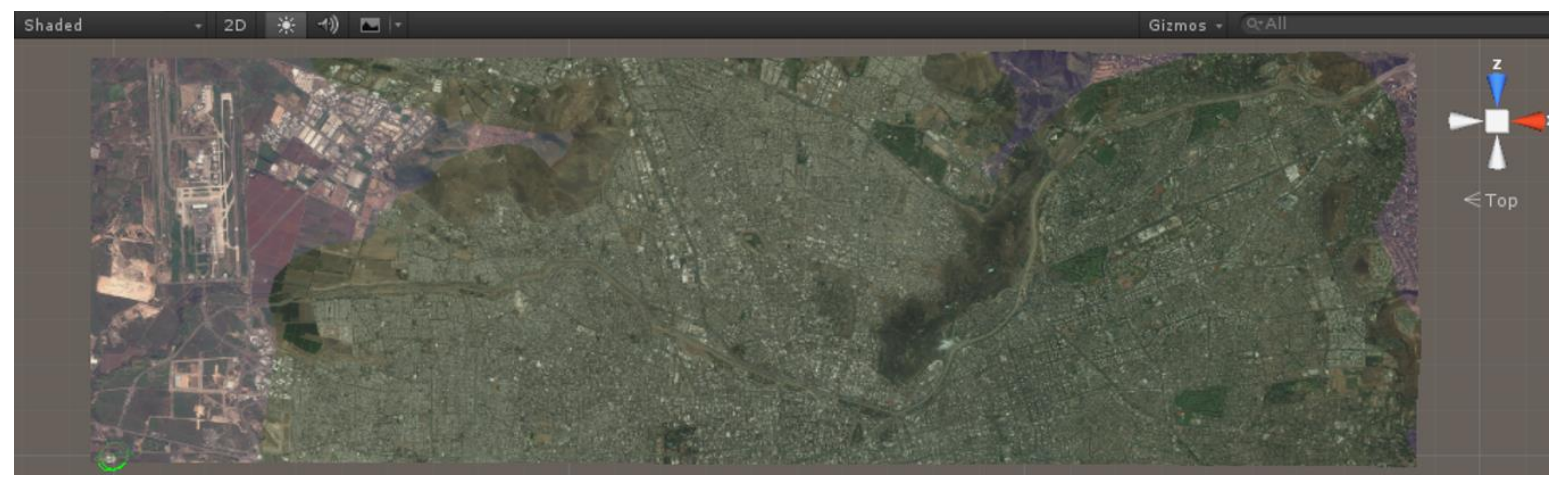

Figure 2: Height map obtained from Google Maps of "Costanera Norte" highway in Santiago, Chile. 


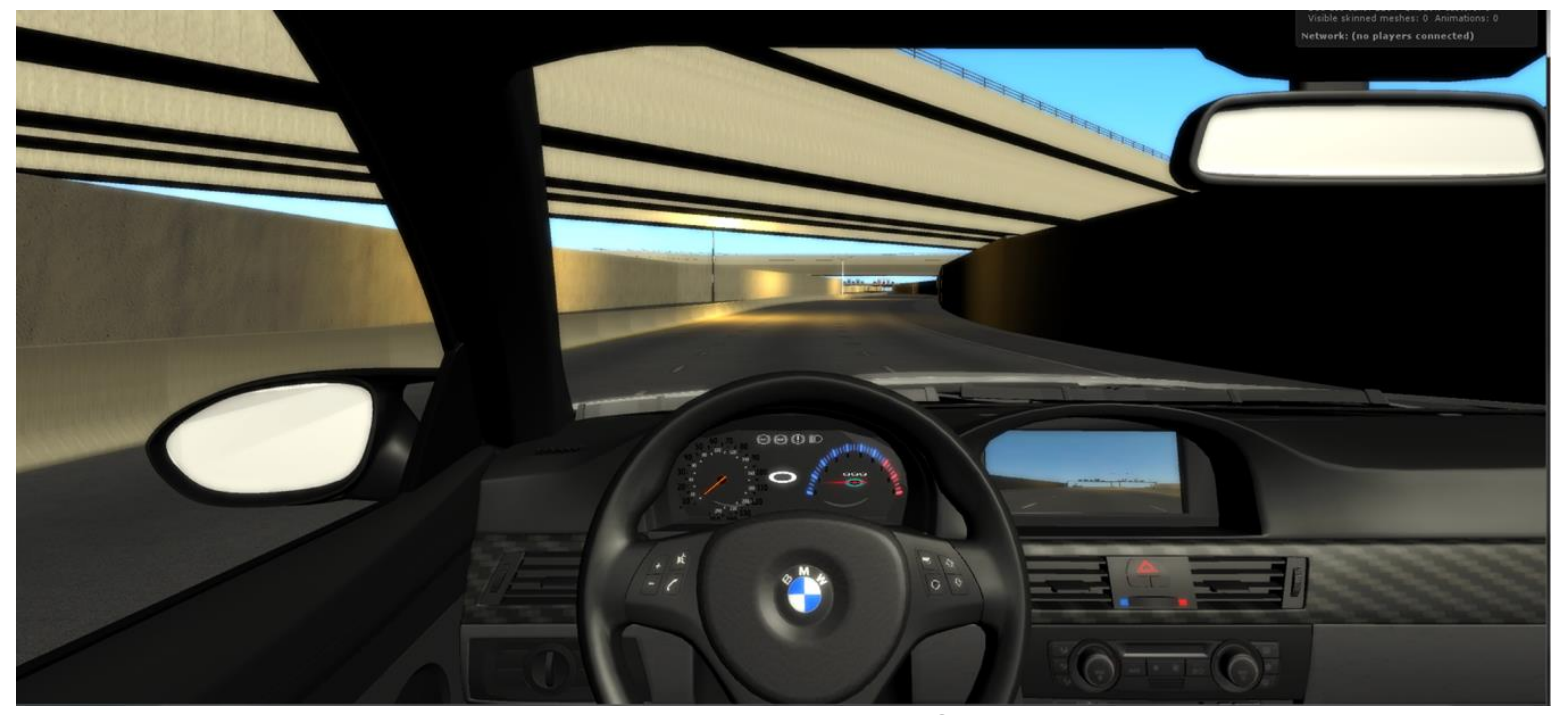

Figure 3: Interior view of the BMW vehicle used in VRStreet, and the view as seen through the windshield of "Costanera Norte" highway in some of its underpasses.

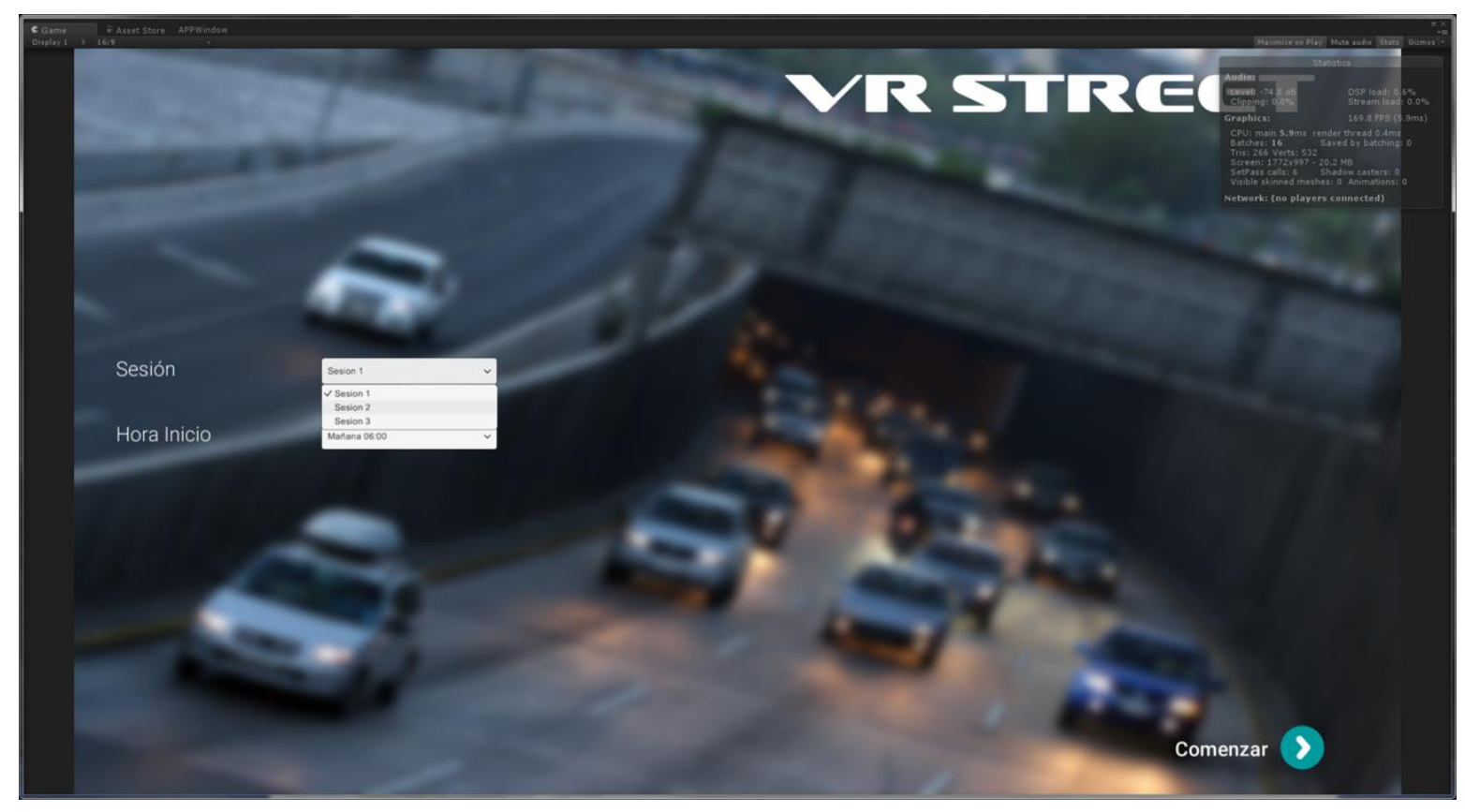

Figure 4: VRStreet main graphical interface in which each session can be selected. 


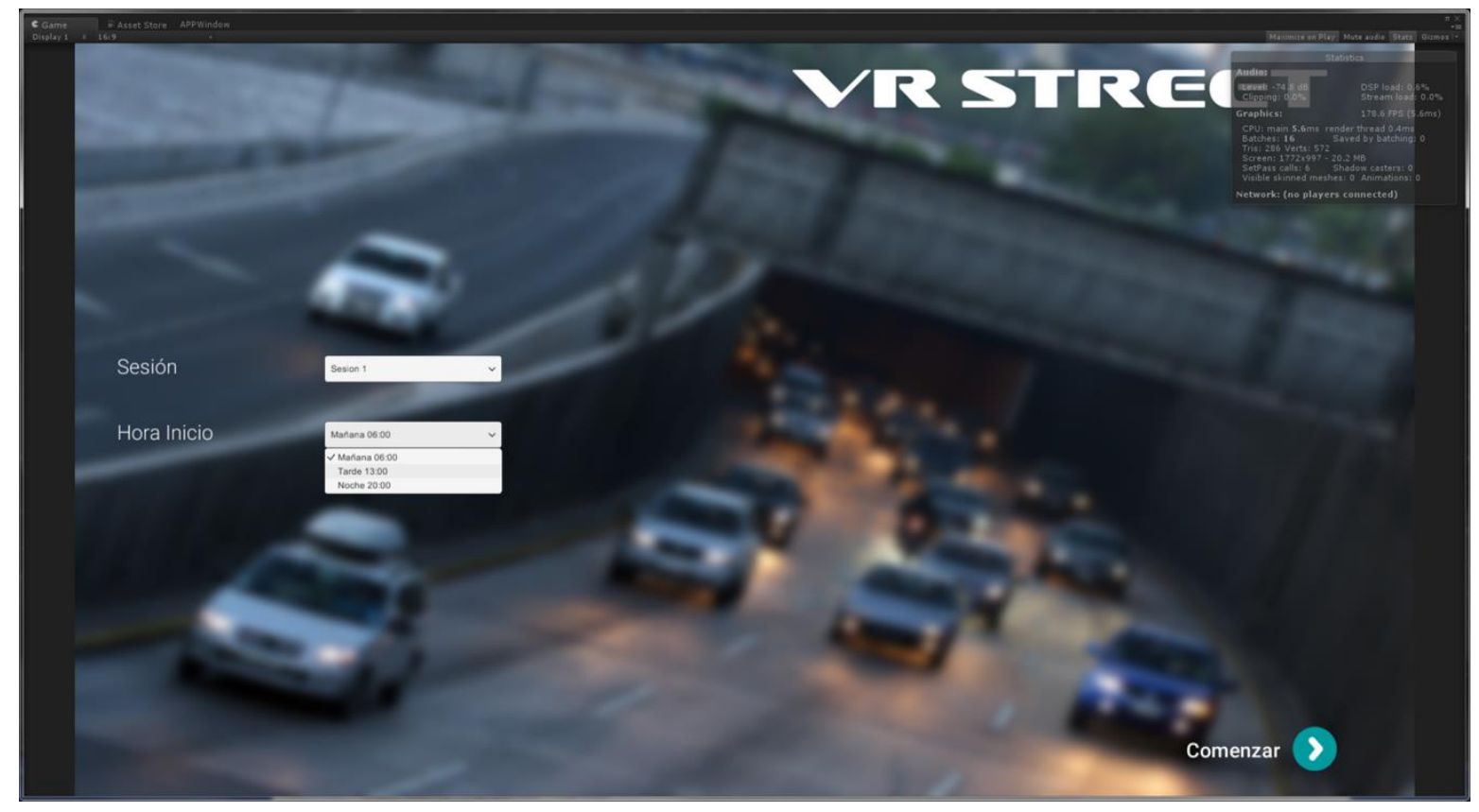

Figure 5: VRStreet main graphical interface in which the desired time frame can be selected (Morning between 6:00 a.m. and 12:59 p.m.; Afternoon between 1:00 p.m. and 7:59 p.m.; and Evening from 8:00 p.m. onwards).

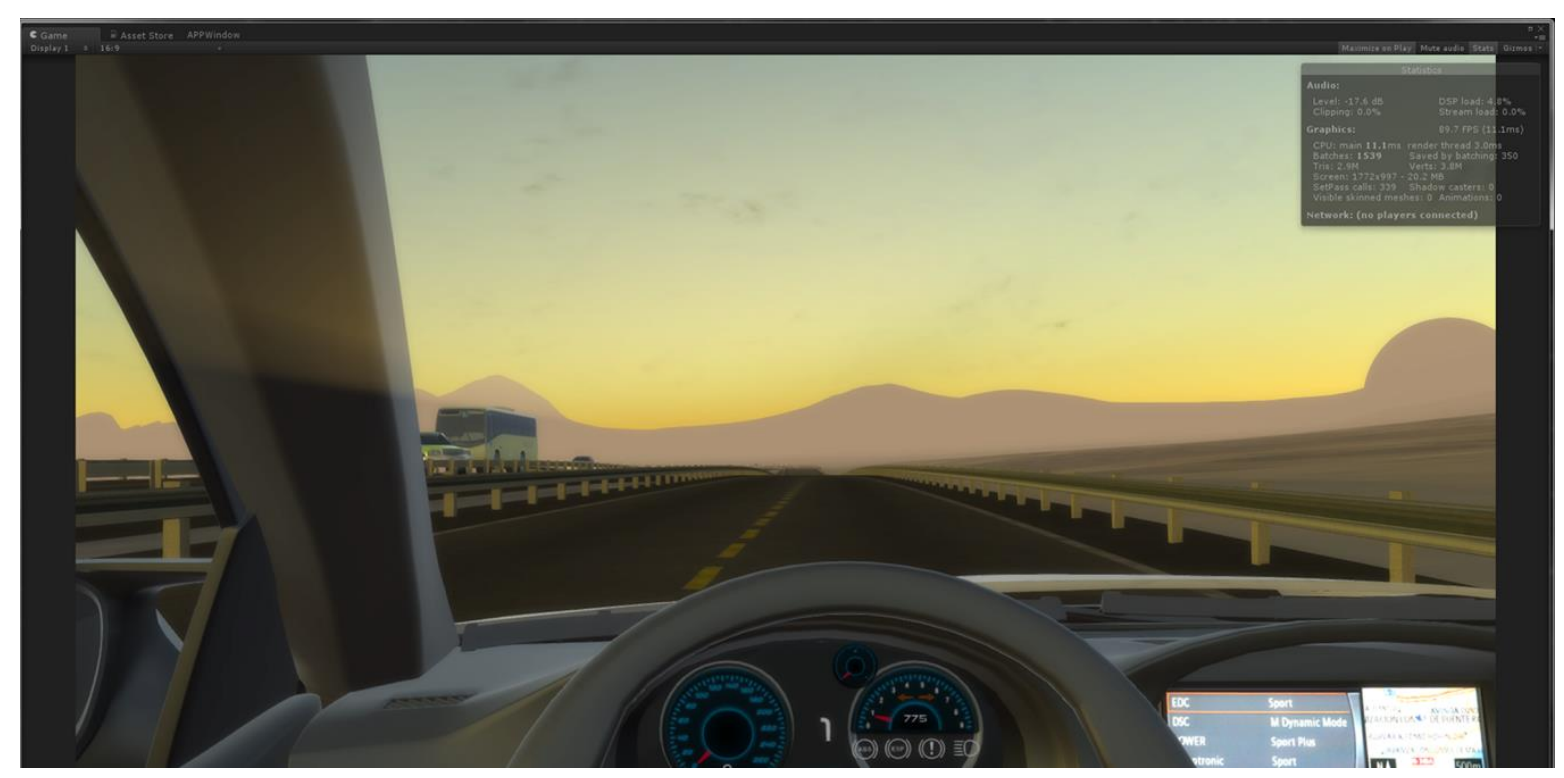

Figure 6: Interior view of the BMW vehicle in which the Costanera Norte highway can be seen in the Morning time frame (between 6:00 a.m. and 12:59 p.m.). 


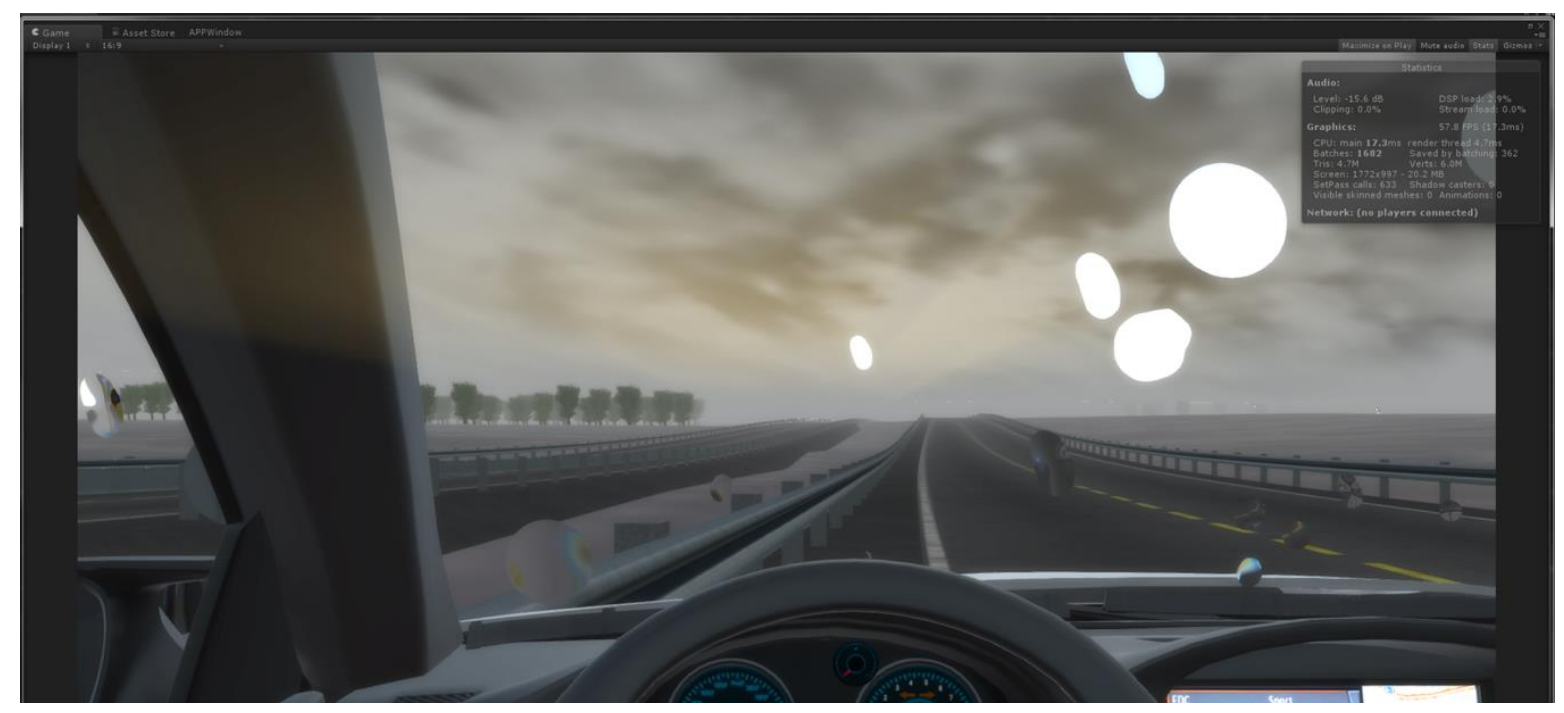

Figure 7: Interior view of the BMW vehicle in which the Costanera Norte highway can be seen in the Afternoon time frame (between 1:00 p.m. and 7:59 p.m.).

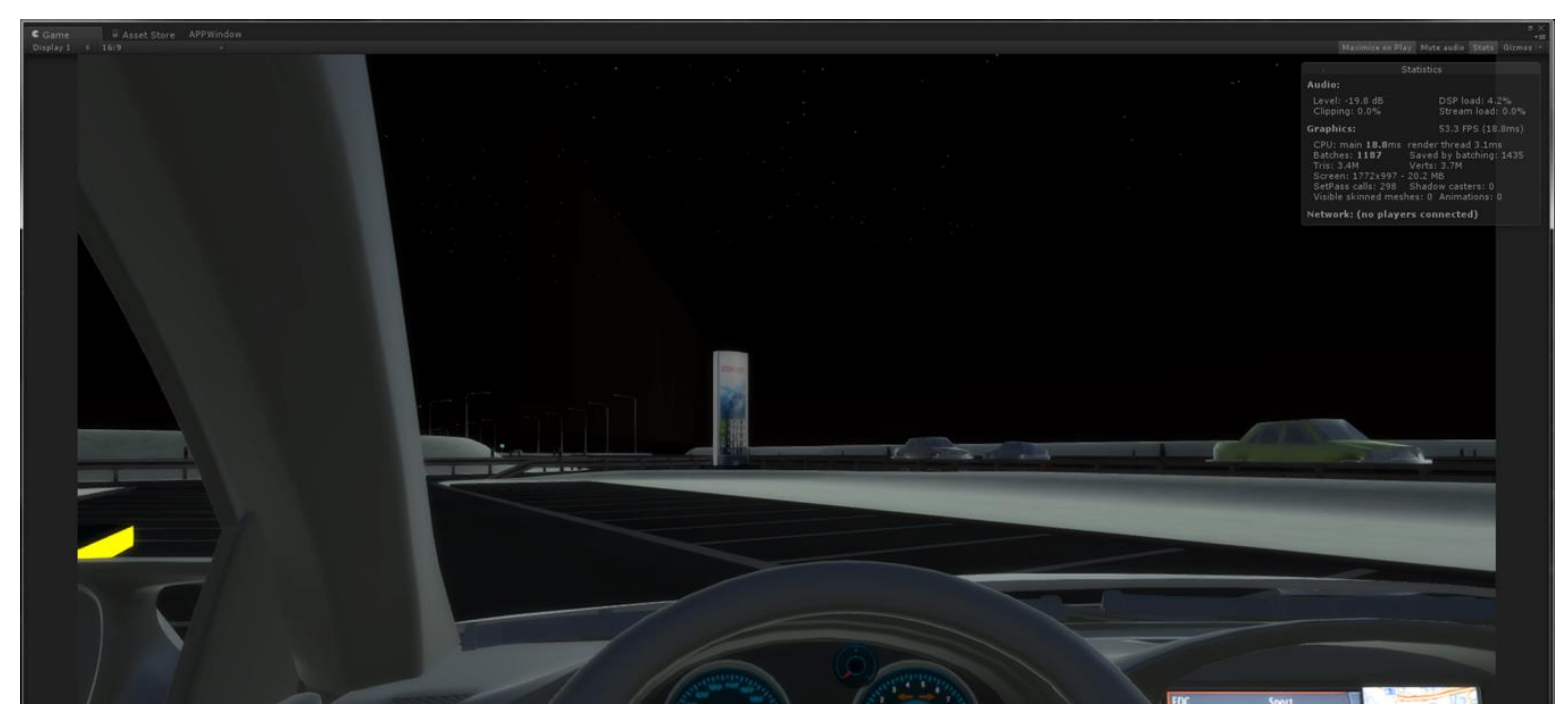

Figure 8: Interior view of the BMW vehicle in which the Costanera Norte highway can be seen in the Evening time frame (from 8:00 p.m. onwards).

\section{ACKNOWLEDGEMENTS}

This Project has been financed by the PIA Project (Academic Division, Clínica las Condes, Santiago de Chile) under the name: "Use of Advanced Virtual Reality Techniques for the Treatment of Certain Phobias". 


\section{REFERENCES}

American Psychiatric Association. (2013). Diagnostic and statistical manual of mental disorders (5th ed., text rev.). Washington, DC.

Ben-Moussa, M, Rubo, M, Debracque, C, \& Lange, W-G. (2017). DJINNI: A Novel Technology Supported Exposure Therapy Paradigm for SAD Combining Virtual Reality and Augmented Reality. Frontiers in Psychiatry, 8, 26. doi:10.3389/fpsyt.2017.00026.

Botella, C, Baños, R, Villa, H, Perpiñá, C, \& García-Palacios, A. (2000). Virtual reality in the treatment of claustrophobic fear: a controlled multiple baseline design. Behavior Therapy, 31(3), 583-595

Botella, C, Osma, J, García-Palacios, A, Quero, S, \& Baños, RM. (2004). Treatment of flying phobia using virtual reality: data from a 1-year follow-up using a multiple baseline design. Clinical Psychology \& Psychotherapy. 11(5), 311-323

Botella, C, Fernández-Álvarez, J, Guillén, V, García-Palacios, A, \& Baños, R. (2007). Recent Progress in Virtual Reality Exposure Therapy for Phobias: A Systematic Review. Current Psychiatry Reports, 19(7): 19:42.

Bouchard, S. (2011). Could virtual reality be effective in treating children with phobias? Expert Review of Neurotherapeutics, 11(2): 207-213. doi: 10.1586/ern.10.196.

Garcia-Palacios, A, Hoffman, H, Carlin, A, Furness, TA 3rd, \& Botella, C. (2002). Virtual reality in the treatment of spider phobia: a controlled study. Behaviour Research and Therapy, 40(9): 983-93.

Gujjar, KR, van Wijk, A, Sharma, R, \& de Jongh, A. (2017). Virtual Reality Exposure Therapy for the Treatment of Dental Phobia: A Controlled Feasibility Study. Behavioural and Cognitive Psychotherapy, 1-7. doi: 10.1017/S1352465817000534.

Gujjar, KR, Sharma, R, \& Jongh, AD. (2017). Virtual Reality Exposure Therapy for Treatment of Dental Phobia. Dental Update, 44(5), 423-4, 427-8, 431-2, 435.

Gregg, L, \& Tarrier, N. (2007). Virtual reality in mental health: a review of the literature. Social Psychiatry and Psychiatric Epidemiology, 42(5): 343-354.

Hamm, AO. (2009). Specific phobias. The Psychiatric clinics of North America, 32(3): 577591.

Kessler, RC, Aguilar-Gaxiola, S, Alonso, J, Chatterji, S, Lee, S, Ormel, J, Ustün, TB, \& Wang, PS. (2009). The global burden of mental disorders: an update from the WHO World Mental Health (WMH) surveys. Epidemiologia e psichiatria sociale, 18(1): 23-33

Krijn, M, Emmelkamp, PMG, Biemond, R, de Wilde de Ligny, C, Schuemie, MJ, \& van der Mast, CAPG. (2004). Treatment of acrophobia in virtual reality: the role of immersion and presence. Behaviour Research and Therapy, 42(2): 229-439. 
Levy, F, Leboucher, P, Rautureau, G, Komano, O, Millet, B, \& Jouvent, R. (2016). Fear of falling: efficacy of virtual reality associated with serious games in elderly people.

Neuropsychiatric Disease and Treatment, 12: 877-881. doi: 10.2147/NDT.S97809.

Miloff, A, Lindner, P, Hamilton, W, Reuterskiöld, L, Andersson, G, \& Carlbring, P. (2016). Single-session gamified virtual reality exposure therapy for spider phobia vs. traditional exposure therapy: study protocol for a randomized controlled non-inferiority trial. Trials, 17: 60. doi: 10.1186/s13063-016-1171-1.

Mitrousia, V, \& Giotakos, O. (2016). [Virtual reality therapy in anxiety disorders].

Psychiatriki, 27(4): 276-286. doi: 10.22365/jpsych.2016.274.276.

Morina, N, ljntema, H, Meyerbröker, K, \& Emmelkamp, PM. (2015). Can virtual reality exposure therapy gains be generalized to real-life? A meta-analysis of studies applying behavioral assessments. Behaviour research and therapy, 74: 18-24.

Rothbaum, BO, Hodges, L, \& Kooper, R. (1997). Virtual reality exposure therapy. The Journal of Psychotherapy Practice and Research, 6(3): 219-226.

Rothbaum, BO, Hodges, LF, Smith, S, Lee, JH, \& Price, L. (2000). A controlled study of virtual reality exposure therapy for the fear of flying. Journal of Consulting and Clinical Psychology, 68, 1020-1026.

Shiban, Y, Schelhorn, I, Pauli, P, \& Mühlberger, A. (2015). Effect of combined multiple contexts and multiple stimuli exposure in spider phobia: A randomized clinical trial in virtual reality. Behaviour Research and Therapy, 71: 45-53. doi: 10.1016/j.brat.2015.05.014.

Shiban, Y, Brütting, J, Pauli, P, \& Mühlberger, A. (2015). Fear reactivation prior to exposure therapy: does it facilitate the effects of VR exposure in a randomized clinical sample? Journal of Behavior Therapy and Experimental Psychiatry, 46: 133-140.

Silverman, WK, \& Moreno, J. (2005). Specific phobia. Child \& Adolescent Psychiatric Clinics of North America, 14(4): 819-843.

Vicente, B, Rioseco, P, Saldivia, S, Kohn, R, \& Torres, S. (2002). [Prevalence of psychiatric disorders in Chile (DSM-III-R/CIDI) (ECPP)]. Revista médica de Chile, 130(5), 527-536. 